\title{
PREDISPOSING FACTORS OF SCABIES AMONG THE PATIENTS ATTENDING SKIN AND VENEREAL DISEASE OUTDOOR OF DHAKA MEDICAL COLLEGE HOSPITAL
}

\author{
AFZALUR RAHMAN MAHMOOD ${ }^{1}$, ZANNATUN NUR $^{2}$
}

\begin{abstract}
:
This cross sectional type of descriptive study was carried out among the patients attending the Skin and Venereal Disease (VD) Out Patient Department (OPD) of Dhaka Medical College Hospital (DMCH) from August 2006 to November 2006 with a view to explore the current situation of scabies and its predisposing factors. In this regard 213 clinically diagnosed scabies contracted patients were interviewed randomly by using pre-tested questionnaire. Risk factors were assessed considering their dwelling places, types of families, number of family members, persons living in each room, using fomites of infected persons, socioeconomic condition, occupation, level of education, regular bathing and cloth washing habit along with age, sex distribution and clinical presentation of scabies. The mean age of the respondents was 13.16 years with a standard deviation (SD) of \pm 5.38 years and majority (36.15\%) was in the age group of 1-5 years. Male, female ratio was 1.15:1. Major level of education was in the group of class I to V(38\%). 50.73\% had family members comprised of 4 to 6 . Majority (38.50\%) belonged to lower middle class (income 3001-6000 taka/month). Among the respondents maximum (54.93\%) were infected by family members. $77.94 \%$ respondents used fomites of affected persons and $66 \%$ respondents shared beds of infected persons. Mean duration of illness was 42 days with standard deviation of \pm 4.47 days. Among the male, majority (82.63\%) had lesion on lower abdomen and buttock. In contrary, $80.28 \%$ female had lesion on hand. $58.68 \%$ presented with papule. The study recommends that emphasis should be given on personal hygiene and life style of people as well as educating them about scabies.
\end{abstract}

Key words: Scabies, Predisposing factors, Skin and VD outdoor

\section{Introduction:}

There is a saying that one cannot hide love, cough and itching from others. The predominant cause of itching in our Bangladesh is the highly contagious parasitic disease called scabies. In this developing country, people being trapped in a vicious circle of poverty, overcrowding, poor housing, malnutrition, ill health; are still fighting with communicable diseases as well as emerging non-communicable diseases. Here $80 \%$ of people, suffering from skin diseases, are suffering from scabies and pyogenic infection. ${ }^{1}$ Although it is observed as sporadic case in developed countries, scabies is endemic in Bangladesh. In parts of Bangladesh, the number of children with the 'itch' exceeds the number to diarrhoeal and respiratory disease combined. ${ }^{2}$ It is considered to be the commonest disease among the patients attending dermatology outpatient department in our country. ${ }^{3}$ Epidemics or pandemics occur in 30 years cycle due to change in immune status of host population. ${ }^{1}$ Two pandemics coincided with the two World Wars. ${ }^{4} \mathrm{~A}$ Third World View on globalization and the impact on health showed many diseases including scabies had been virtually eradicated in many countries including Iraq before the war. But it is making a comeback in this once-medically advanced country. ${ }^{5}$ As it is not a reportable disease and based on variable notification, the incidence of scabies is difficult to ascertain. However it is a worldwide public health problem with global occurrence of 300 million cases each year. ${ }^{6}$

Scabies is highly transmissible but benign, treatments are available and infectivity can be controlled. As a

1. Lecturer, Department of Community Medicine, Dhaka Medical College

2. Post Graduate Trainee, Department of Medicine, Dhaka Medical College Hospital 
result, priority has to be given to preventive measures and on Bangladesh perspective, it has gained a major attention in the field of communicable disease. As it can be called by many names like contagious disease, sexually transmitted disease, water related disease, fomite borne disease; it is caused by wide range of predisposing factors. ${ }^{7}$ This study is a sincere attempt to explore these factors.

\section{Patient and Methods:}

This cross-sectional type of descriptive study was conducted at the Skin and VD OPD, DMCH from August 2006 to November 2006. A questionnaire was prepared as research instrument considering the variables \& objectives of the study. Then it was pretested and necessary correction \& changes were incorporated according to pretest result. Study population included all the patients having scabies attended at Skin \& VD OPD, DMCH during the period from $12^{\text {th }}$ October to $19^{\text {th }}$ October 2006. Diagnosis of scabies was made clinically by taking careful history including that of close contacts and family along with meticulous examination of lesions. Before collection of data all the patients were briefed about the purpose of study and informed consent was obtained. In case of infants and children, their parents or attendants were interviewed. Total sample size was 213 and was selected conveniently. After collection of data, they were checked and verified manually to make the data more consistent. Data analysis was performed by using Statistical Package for Social Science (SPSS, version 11.5). Univariate analysis was performed to observe the frequencies. Descriptive statistics with percentage, pie charts and bar diagrams were applied.

\section{Results:}

The mean age of the patients was 13.16 years and the $\mathrm{SD}$ was \pm 5.38 years. Total 213 respondents were distributed into 6 age groups. Lion share of them (36.15\%) were in the age group of $1-5$ years (Table I). Number of male patients were 114 (54\%) and 99 (46\%) were female. 113 respondents were under 15 years of age, so excluding them, 53 (53\%) patients were unmarried, 42 (42\%) married, followed by widow3 (3\%) and divorced $2(2 \%)$ respectively. Among the 147 respondents above 5 years of age, majority 56 (38.10\%) were in class I to V group (Table-2) and 62(29.1\%) were students. Figure-1 depicts the occupations of the patients. There were 5 groups according to their monthly family income and $82(38.50 \%)$ patients were in the lower middle class group (Table- III). Table-IV shows the dwelling places of respondents. 141 (66\%) respondents belong to single family and 72 (34\%) belong to joint family. Four groups were made according to their number of family members. Majority (107, $50.73 \%$ ) respondents had family members between 4 6 and the mean of the persons living in each room was 4.48 with SD of \pm 8.53 (Figure-2). Maximum respondents 117 (54.93\%) were infected by family members. A good number (166, 77.94\%) of patients used fomites of the infected persons. 141 (66\%) patients shared the bed with infected persons and 179 (84\%) did not wear the clothes of the infected person (Figure 3). $187(87.80 \%)$ respondents have the habit of bathing regularly and $168(78.88 \%)$ have the habit of washing clothes regularly. Regarding the discomfort due to scabies, all patients complained of itching. 55 (25.82\%) respondents complained of disturbance of sleep. Mean duration of illness was 41.97 days with the SD of \pm 4.47 days. Majority of males, 176 (82.63\%) had lesions on "lower abdomen \& buttock" and in case of females "hand" was involved predominantly (171, 80.28\%).

\section{Table-I}

Distribution of the respondents by age

\begin{tabular}{lcc}
\hline Age (year) & Number & Percentage \\
\hline $1-5$ & 77 & $36.15 \%$ \\
$6-10$ & 26 & $12.20 \%$ \\
$11-18$ & 45 & $21.13 \%$ \\
$19-29$ & 42 & $19.72 \%$ \\
$30-45$ & 18 & $8.45 \%$ \\
$46-60$ & 5 & $2.35 \%$ \\
\hline Total & 213 & $100 \%$ \\
\hline
\end{tabular}

Table-II

Distribution of the respondents by their level of education

\begin{tabular}{lcc}
\hline Level of education & Number & Percentage \\
\hline Illiterate & 18 & $12.25 \%$ \\
Able to write name & 9 & $6.12 \%$ \\
Class I to V & 56 & $38.10 \%$ \\
Class VI to X & 35 & $23.81 \%$ \\
S.S.C.lequivalent & 13 & $8.84 \%$ \\
H.S.C./equivalent & 13 & $8.84 \%$ \\
Graduation \& above & 2 & $1.36 \%$ \\
Informal education & 1 & $0.68 \%$ \\
\hline Total & 147 & $100 \%$ \\
\hline
\end{tabular}


JM Vol. 9, No. 2 Predisposing Factors of Scabies among the Patients Attending Skin and Venereal Disease Outdoor of DMCH

Table-III

Distribution of respondents according to the monthly family income

\begin{tabular}{lcc}
\hline Income & Number & Percentage \\
\hline Very poor(<Tk.1000) & 2 & $0.94 \%$ \\
Poor(Tk.1000-3000/-) & 58 & $27.23 \%$ \\
Lower middle class(Tk.3001-6000/-) & 82 & $38.50 \%$ \\
Middle class(Tk. 6001-10,000/-) & 48 & $22.53 \%$ \\
Upper middle class(> Tk. 10,000/-) & 23 & $10.8 \%$ \\
\hline Total & 213 & $100 \%$ \\
\hline
\end{tabular}

Table-IV

Respondents' distribution by places for dwelling

\begin{tabular}{lcc}
\hline Places for dwelling & Number & Percentage \\
\hline Slum & 31 & $14.55 \%$ \\
Colony & 58 & $27.23 \%$ \\
Mess & 15 & $7.04 \%$ \\
Hostel & 10 & $4.69 \%$ \\
Camp & 1 & $0.47 \%$ \\
Flat & 49 & $23.01 \%$ \\
Private house & 49 & $23.01 \%$ \\
\hline Total & 213 & $100 \%$ \\
\hline
\end{tabular}

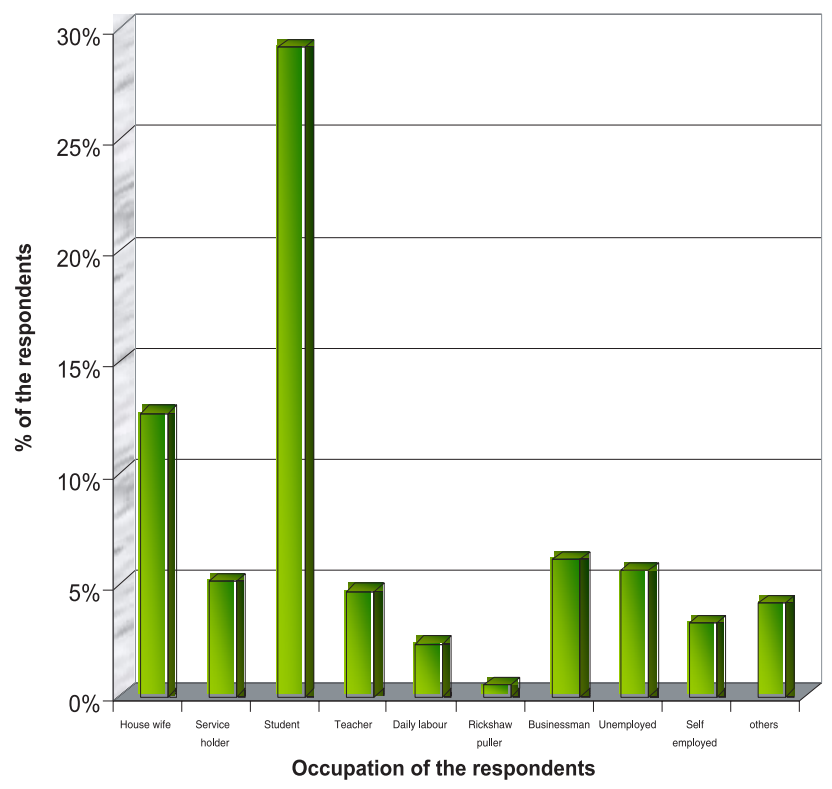

Fig.-1 : Distribution of respondents according to their occupation

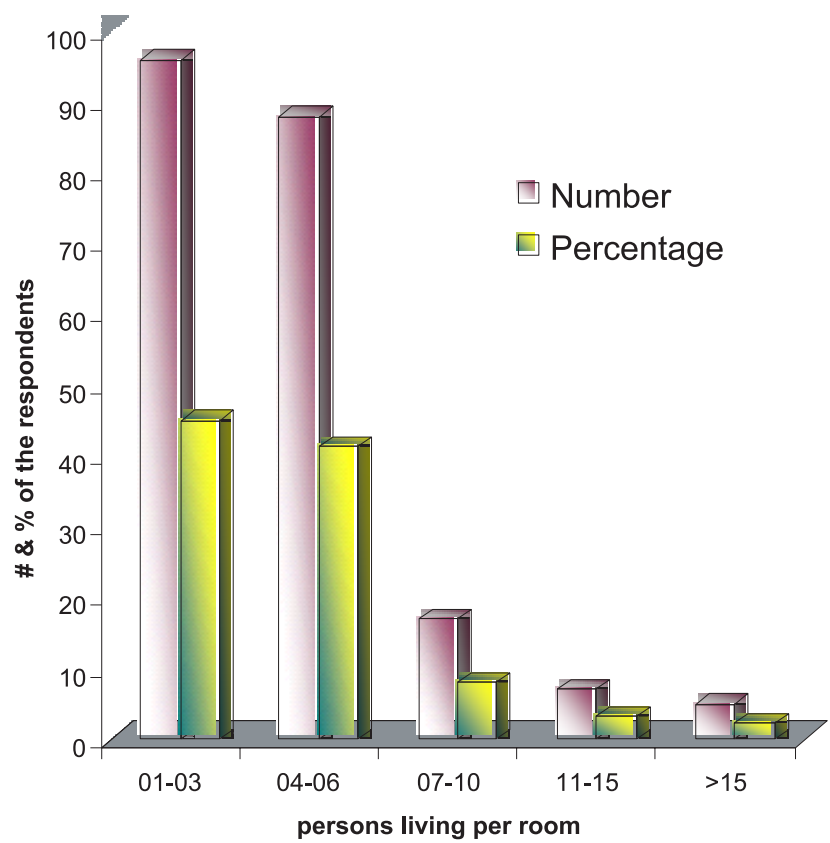

Fig.-2 : Patients' distribution regarding number of persons living in each room

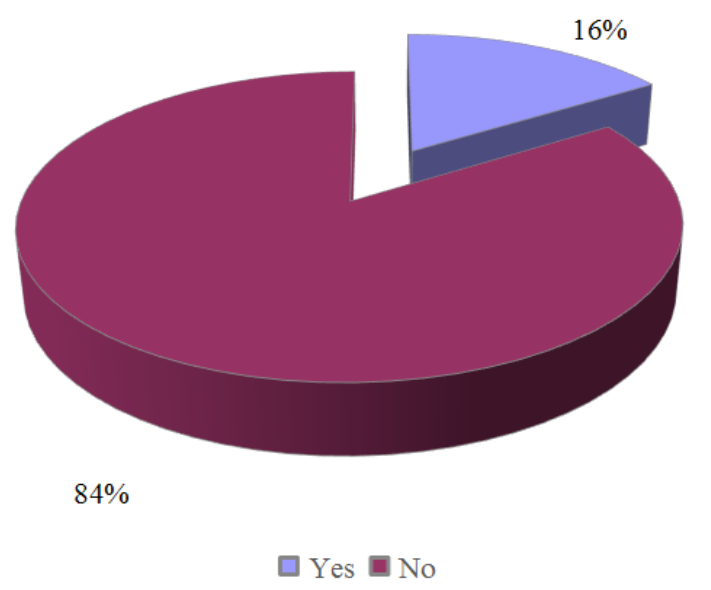

Fig.-3: Distribution of the respondents according to wearing clothes of infected persons

\section{Discussion}

Scabies is an age old disease being reported for more than 2500 years. ${ }^{2}$ However, the disease was first ascribed to the very small wingless mite called the Human Itch mite (Sarcoptes scabei var. hominis) by Giovan Cosino Bonomo in $1687 .^{2}$ Man is the predominant host of scabies. Uncommon human infestation with animal strain (i.e. Sarcopte scabiei var. canis) can occur specially from dogs. ${ }^{8}$ The human scabies is characterized by pruritic papular lesions and house the female mite and its larvae in its burrow. The site of predilection are chiefly the finger webs, 
wrists, axilla, areola, area around the umbilicus, waist, genitalia, and the buttocks. ${ }^{9}$ Atypical sites of involvement such as palms, soles, face and scalp were significantly commoner in children less than two years of age. ${ }^{10}$ Scabies is generally a nuisance on account of itching, rash and its ability to spread among people. ${ }^{11}$ However it can indirectly lead to long term morbidities which can make life miserable. Superinfection by group A Streptococci may result in fatal post streptococcal glomerulonephritis (PSGN). Other complications of include impetigo, furunculosis, cellulitis, pyelonephritis, abscess, pyogenic pneumonia, sepsis \& death. ${ }^{2}$ Scabies spreads predominantly by personal contact that is sleeping together or by close contact with fomites (contaminated articles such as clothing, bedding, towels, cups, toys, books, door handles, taps etc) or by shaking hands. It is prevalent where people are crowded together or have frequent contact and is most common among slum dwellers, school children, families, roommates and sexual partners. ${ }^{12}$ Two studies have linked susceptibility of scabies to HLA-A11 antigen. An increase in IL-4 and immunocompromised patients are at risk of developing fulminant and highly infectious form of scabies known as crusted or Norwegian scabies. ${ }^{13}$ Itching is often minimal or absent, since patients do not mount a significant immune response to the organism. This variety of scabies often is responsible for mini epidemics of conventional scabies infestations in nursing homes and other institutions. ${ }^{14}$ Risk factors for being infected with scabies among nurses, physical therapists or health care workers included working in the AIDS service. ${ }^{15}$ Inability to scratch is a plausible cause of higher incidence of scabies in Down's syndrome and mental retardation. ${ }^{14}$ As it usually does not make a subject bed ridden, people are reluctant to treatment and may increase incidence.

Scabies is a very exciting disease as its occurrence is related with a great number of variables and the disease is manifested by a variety of lesions. Scabies was found to have no respect for age, sex, place, occupation, social status or race. It is prevalent throughout the world in all age groups and in both sexes, but the incidence is high in underdeveloped countries due to overcrowding and poor personal hygiene. ${ }^{16}$

In developing countries scabies tends to have higher prevalence in pre school children and the same is observed this study. It reveals that males (54\%) are more affected than female (46\%) which might be due to less case reporting to the health care centres by female patients. Although scabies is a sexually transmitted disease, $53 \%$ of patients in our study were unmarried. The plausible reason may be due to most of respondents were in the age group which is not suitable for marriage.

In report no. 53 of health sector programme in Bangladesh prevalence ratio of scabies for illiterate vs. literate was found to be $2.03 .{ }^{17} \mathrm{We}$ found majority of the patients $(56,38.10 \%)$ in class I to $V$ group which indicates relation of the disease with lack of knowledge. But the low mean age of patients (13.16 year) is a contributing cause here.

Regarding occupation $29.1 \%$ were students and $12.68 \%$ were housewives in the current study. While another study shows most of the respondents belonged to agricultural workers ${ }^{18}$ which reflects rural urban distribution.

Few studies reveal that scabies is significantly more prevalent among families of large size, high crowding index, low socioeconomic condition and those receiving their water supply from a hand pump. ${ }^{19}$ We found majority respondents in the lower middle class. Due to acceptancy of modern concept of nuclear family by the city dwellers lion share of our respondents belong to single family, live in the colonies, had family members between 4-6 and 1-3 persons living in each room. However, scabies is a disease of both clean and dirty people, e.g. in Denmark there have been 1 million cases since 1900 and the prevalence is identical to that at the turn of the century despite a marked improvement in the standards of living. ${ }^{20}$

Scabies may be called familial or house hold infection, because the disease tends to spread by close contact through families. Current study affirms this concept. Not only the family members, but also relatives and colleagues may act as a source of infection. High prevalence rate of scabies among the pre school and school children may be due to greater chances of mixing at class rooms and playgrounds.

In a study $64 \%$ of dust samples obtained from 37 confirmed cases' rooms revealed live mites and they were most often recovered from bed linen, clothes, bedroom floors, overstuffed chairs, and couches. Realizing that mites can easily live for at least 3 days off the skin surface, that they have host-seeking behavior, and that they exist alive on inanimate objects, 
it becomes apparent that one has a vast potential of fomite transmission who enters the room or house of a scabietic patient. ${ }^{9}$ Using fomites of infected person was found to be an important positive predisposing factor for the evolution of scabies in this study.

Despite the suggestion that bathing less than 3 times a week, change of clothes less than 2 times a week and drug abuse are significantly associated with scabies ${ }^{21}$ presenting study observed regular bathing and cloth washing habit among majority of respondents. In fact, scabies is not influenced by hygiene practices or the availability of water, as demonstrated by institutional outbreaks where high standards of hygiene exist, and by the experience among Kuna Indians, the indigenous population of Panama, a population in which careful daily personal hygiene is traditional. ${ }^{22}$

\section{Conclusion:}

Scabies continues to be a silent health problem in our community and in complicated form, it has some grave consequences. Scabies is such a health problem, good control can be achieved with increased awareness, better case finding, education of the staff at the rural health unit and by taking simple means such as improvement of personal hygiene and other healthful living. To develop awareness about the present magnitude of scabies in all section of community emphasis must be given at the primary level of health care. On the basis of information obtained and subsequent discussion with other literature it is hopeful that the findings of this study may be a useful tool for future research and planning for preventing and control of scabies and its compilations.

\section{References:}

1. Islam SMN, Begum R, Islam T. Socio-demographic characteristics of scabies patients attending skin and venereal disease out patient department of Khulna Medical College Hospital. Bangladesh J dermatol venereal leprol 2003; 20(1): 16-18

2. Binder WD. Scabies. In: e-Medicine.Accessed June 2006.

3. Barbhuiya AK. Epidemiology of scabies in Dhaka city (Dissertation) Dhaka: IPGMR, 1976.

4. Andrews JRH. Scabies in N Z Int J Dermatol 1979;18: 545-52

5. ICRC Report, December 1999; 14: 6

6. Schofield OMV, Rees JL. Skin Disease, Some common skin infections and infestations. In: Davidson S, eds. Davidson's Principles \& Practice of Medicine. Nineteenth edition. Elsevier Science Limited 2005: 1085
7. World Health Organization. Water sanitation and Health. Reviewed by staff \& experts from the water, Sanitation and Health Unit (WSH). Water-related Diseases 2001: 1.

8. James M. Essays on Tropical Dermatology. Excrepta Medica Amsterdam 1972: 199-207.

9. Burkhart C G, Burkhart C N, Burkhart M K. An Epidemiologic and Therapeutic Reassessment of Scabies. Cutis; 65(4): 233-40.

10. Wakhlu I, Thakur S, Govil YV, Rastogi AK. Clinical profile of scabies in north Indian children. Indian Pediatrics 1988; 25(11): 1050-3.

11. Chosidow O. Clinical Practice, Scabies. New Eng J Med 2006; 354: 1718-27.

12. Tvedten S. Facts About Scabies, The best control for lice \& Scabies, The Best Control II. Chapter 16. P-764.

13. Kristoffer K, Guldbakke, Khachemoune A. Crusted scabies: a clinical review. J drugs dermatol 2006: 1

14. Kramer WL, Mock DE. Joint publication of the University of Nebraska and Kansas State University 1997: 86-88

15. Anonymous, Department of Epidemiology, John's Hopkins School of Hygiene and Public Health, The John's Hopkins University, Baltimore, USA; 22(1): 13-18.

16. Sethupathy, N, Velu KM, Sentamilselvi G, Kamalam A, Tambiah AS. Scabies In: A Tropical Skin Clinic. Current Medical Practice July 1991; 35(7): 181-7.

17. Report No. 53. Health Sector Programme in Bangladesh: Promoting Participation and Gender Equity, January 2003: 1-35.

18. Islam AKMS. Prevalence of scabies in a village of Bangladesh. Bangladesh J Dermat Venereol Leprol Jan 1989; 6(1): 22-25.

19. Khan MA. Socio-demographic differentials of patients having scabies attending the Skin and venereal disease out patients department of Bangabandhu Sheikh Mujib Medical University (BSMMU), Dhaka (Dissertation). Dhaka: NIPSOM, 2005.

20. Syllabus - Geriatric Practice in Clinical Medicine. The American Geriatrics Soc. 22(7): 3: 47-51.

21. Negi KS, Kandpal SD, Prasad D. Pattern of skin diseases in children in Gharwal region of Uttar Pradesh. Indian Pediatrics 2001; 38: 77-80.

22. McCarthy JS, Kemp DJ, Walton SF, Currie BJ. Scabies: more than just an irritation. Postgraduate Med J 2004; 80: 382-7. 